\title{
Erratum to: Long-term optical variability properties of blazars in the SDSS Stripe 82
}

\author{
Lisheng Mao $^{1}$ (D) Xuemei Zhang ${ }^{2}$
}

Published online: 11 October 2016

(C) Springer Science+Business Media Dordrecht 2016

Erratum to: Astrophys Space Sci (2016) 361:345

DOI 10.1007/s10509-016-2934-6

The original, online publication showed 32 subfigures in Fig. 1, the last 16 of which were duplicates of the first 16 .
Figure 1 should have shown 31 (different) subfigures. The original article was corrected.

The online version of the original article can be found under doi:10.1007/s10509-016-2934-6.

$凶$ L. Mao

maolisheng@ynnu.edu.cn

1 Department of Physics, Yunnan Normal University, Kunming 650500, China

2 School of Mathematics and Statistics, Qujing Normal University, Qujing 655011, China 